\title{
La experiencia lectora escolar: posibilidad en la construcción de vida de los alumnos de secundaria
}

\author{
Elia Arzate López
}

\section{Resumen}

n el presente trabajo se reúnen los -1 resultados de una investigación de corte cualitativo. En ella se retomaron algunos elementos propuestos por $\mathrm{Bu}$ enfil (2011) sobre cómo se realiza investigación social. El objeto de estudio se situó en secundaria, en la asignatura de Español y específicamente en el acto de leer que genera la construcción de Experiencias lectoras escolares.

Una experiencia lectora escolar es una categoría intermedia (Buenfil, 2008) que vincula las categorías teóricas de Schütz $(1993,1995)$, Mandoki $(2006,2008)$ y Freire (1986) con categorías empíricas para expresar un fenómeno que comúnmente pasa desapercibido. Es un evento en el que la práctica lectora trasciende el espacio áulico y se incorpora a la construcción de vida del actor-alumno. Para ejemplificarlo se documentaron dos casos del ciclo esco- lar 2013-2014. Se trató de alumnas que cursaban el segundo grado, Berenice en una secundaria general de Ecatepec, Estado de México y Nayeli en una secundaria técnica de tiempo completo en Metztitlán, Hidalgo. Ambas dieron testimonio de cómo un texto impactó su mundo al ser leído en la cotidianidad de la actividades del aula de clases.

La intención de señalar que en ocasiones al leer en la escuela se construyen experiencias, pretende fomentar el reconocimiento de una perspectiva distinta a la que predomina (competencia lectora) y que lejos de oponerse se espera complementar la mirada del docente hacia su práctica, así como propiciar la reflexión para repensar el papel de las instituciones educativas en la formación de lectores en México.

Palabras clave: experiencia lectora escolar, actor-alumno, secundaria, español. 
REVISTA DE INVESTIGACIÓN EDUCATIVA DE LA REDIECH N. 7 ISSN: 2007-4336

\section{Introducción}

Para estimar que en el acto de leer se construyen experiencias es necesario reconocer el panorama desde el cual se plantea, de ahí que se inicie examinando la concepción de lectura que predomina en la educación básica y particularmente en secundaria. En este nivel educativo al hablar de lectura dos de los términos más comunes son: competencia lectora y lector competente, para referirse a las características idóneas de tal actividad. Las pruebas estandarizadas a nivel nacional ${ }^{1}$ e internacional ${ }^{2}$ y los programas ${ }^{3}$ que establece el Estado arrojan resultados que se analizan en función de interpretaciones numéricas. Uno de los objetivos es determinar cómo y cuánto lee el alumno, posicionándolo en diferentes niveles mediante una escala de valores. De este modo la lectura en el aula con frecuencia se reduce a una actividad homogeneizante que discrimina al lector más "apto" del que no lo es.

En los análisis cuantitativos se deja de lado la posibilidad de rescatar otros aspectos que coexisten en el acto de leer, así lo explica el Profr. Sergio (Metztitlán, Hgo.): “[...] la comprensión lectora, la velocidad, la dicción, eso no te da parámetros de que el alumno [...] disfrute la lectura [...] que la contextualice, que la recree como vivencia." (D1EP-PS1-23/10/2013:8-9). Tampoco se consideran algunos efectos que los textos producen durante la recepción y que difícilmente puede ser medidos, sirvan de ejemplo las palabras de una alumna (Metztitlán, Hgo.): “[...] a veces yo quisiera estar $<<$ empieza a llorar>> adentro de esas historias en las que leo, que en mi vida real" (D20EP-AN1-27/11/2013:10).
Admitir dichos efectos conlleva a discernir, por otro lado, que el lector/alumno es considerado un sujeto fragmentado, recortado, es decir, al evaluar su competencia lectora es disociado de su entorno natural. Sin embargo los estudiantes no solo son estudiantes, son sujetos integrales, son amigos, primos, hermanos, empleados, quizá deportistas, etc.

Ahora bien, de acuerdo a lo expuesto anteriormente es necesario abrir horizontes en la práctica docente. Con la finalidad, no de ensombrecer el camino andado y de plantear otra alternativa que funja como panacea, sino de superar fronteras permitiendo una conciliación entre lo que existe a la luz de todos y lo que está ahí pero que permanece oculto. Es decir, construir una visión a partir de reconocer que además de los atributos de los índices de lectura a nivel macro, es posible alargar la mirada hasta reparar en que leer trastoca, leer transforma, leer impacta en la construcción de vida, por lo que en un intento de abarcar lo que ello implica, en esta investigación se le situó en el marco de una experiencia.

Analizar cómo el estudiante es capaz de experienciar al leer, de vivir una práctica lectora escolar, significó atender dos valoraciones: una, considerar al lector/alumno como un ser sensible, integral, en constante conformación y en continua interacción sociocultural a lo largo de su vida. Y dos, vislumbrar que al interior de la experiencia lectora escolar existen diferentes matices entretejidos entre sí, mismos que a partir del trabajo teórico y empírico han sido denominados: dimensión epistemológica, dimensión estética y dimensión sociocultural. 
Para cerrar este apartado cabe señalar que si el acto de leer algunas veces representa la materia prima de la constitución de algunas experiencias en el ámbito escolar, ello no significa que es la única manera de construir experiencias o que éstas son en su totalidad las experiencias que vive el alumno.

\section{La experiencia lectora escolar de las alumnas que conformaron el caso de estudio}

Uno de los hallazgos más importantes en esta investigación fue reconocer que en la clase de Español en secundaria, es posible recuperar experiencias lectoras escolares construidas en esta asignatura, o bien, algunas otras de grados anteriores; en el segundo caso se corroboró como éstas perduran a pesar de los años.

\section{Berenice: "El principito"}

Berenice tiene 14 años y asiste a la Secundaria Oficial No. 161 Juan Escutia, en Ecatepec, Edo. de México. En la actividad de Club de lectores, que se realiza todos los viernes en Español, leyó la novela El principito, con la cual se inspiró para modificar la actitud hacia su hermano menor de nueve años. Ella expresó sentir una especie de rechazo hacia el pequeño debido a que solo es hijo de su papá, fue concebido fuera del matrimonio y posteriormente incorporado a la familia. Cabe señalar, que se detalla la situación con el propósito de resaltar la trascendencia de que Berenice haya decidido enfrentar una tensión en su vida cotidiana. Esta la experiencia en voz de la alumna:

[...] a raíz de ese libro que... que yo leí con la maestra de Español [...] $E l$ principito [...] me hizo recordar todo lo que le hacía a mi hermano [...] me hizo reflexionar muchísimo fue así como... como si me hubieran dicho: ¡Berenice reacciona! $Y$ entonces antier él me pidió que le ayudara con su tarea y en lugar de decirle que estaba ocupada, que no podía o que no quería, dejé las cosas que estaba haciendo para dedicarle por lo menos diez minutos y ayudarle. Entonces me sentí mejor y ya no peleamos y ya no le grité, ni él no me dijo nada y pues fue mejor [...] (D25EP-AB1-11/04/2014: 16).

\section{Nayeli: Fábula de Esopo "El negro" y texto "Discriminación"}

Nayeli tiene 14 años y estudia en la Secundaria Técnica No. 5 General Emiliano Zapata ubicada en Metztitlán, Hgo. Cuando cursaba el quinto grado de primaria tenía tres compañeras que le pusieron un reglamento para que pudieran ser sus amigas. Por ejemplo: ya no podía jugar con muñecas, debía tener novio, tenía prohibido juntarse con "nacos" y era necesario aceptar que los demás eran inferiores a ellas. Sin embargo, la profesora de Nayeli en ese grado, trabajó en un mismo día dos textos (Fábula de Esopo El negro y texto Discriminación del libro de Formación Cívica y Ética) que la impactaron y detonaron la decisión de cambiar de amistades y disculparse con Eli, otra alumna a la que Nayeli y varios integrantes del grupo agredían tanto física como verbalmente. Así lo narra ella:

[...] ]antes cuando iba en la primaria eh... iba una niña en mi salón pero era muy pobre, muy humilde y todos 
la discriminábamos y le decíamos muchas cosas feas, pero yo me juntaba con un grupo de amigas [...] se creían mucho, mucho y... y este pues ellas eran las que más le decían cosas y pues yo me dejé llevar por eso y les seguí la corriente, pero después de que leí de que todos éramos iguales [...] ya no me junté con ellas y pues le pedí perdón a esa niña porque yo era la que me había equivocado y le había dicho muchas cosas feas y... y pues la lastimé [...] (D20EPAN1-27/11/2013: 13-14).

\section{Estrategia metodológica}

De la construcción de esta investigación se desea resaltar, en cuanto a la metodología, parte del diseño del trabajo de campo. A la hora de elegir técnicas de investigación surgieron las siguientes interrogantes: ¿se puede observar una experiencia lectora escolar?, ¿de qué manera dar cuenta de que el alumno de secundaria ha vivido una experiencia lectora escolar? A partir de estas preguntas fue necesario recurrir a otra categoría intermedia (Buenfil, 2008), pero esta vez como técnica de investigación: $L a$ red lectora.

Se requería rastrear cómo se entretejen en una especie de "red" los espacios, las personas y los momentos de la vida cotidiana del actor-alumno en los que se proyecta su experiencia lectora escolar. En la red lectora se funden los componentes de la observación (Rodríguez et al., 1999) y la entrevista en profundidad (Taylor y Bogdan, 1987) para la interpretación de un referente empírico en específico.

Si se considera que una de las diferencias entre lector y autor, es que el primero se ubica frente a la comprensión del mundo del otro (Freire, 1986), es decir, que el lector se sitúa en un segundo plano porque contempla el placer de alguien más (Barthes, 2004). Es posible evidenciar que, de acuerdo a la red lectora de las alumnas, en una experiencia lectora escolar desplazan esta posición para leer el mundo por sí mismas. Berenice al decidir ser más paciente y tolerante con su hermano menor, descubrió que podía darle continuidad a esta actitud en casa con su mamá, en su comunidad con los vecinos y en la escuela con un amigo (Ver esquema 1). Por otro lado Nayeli al cambiar de amigas y dejar de agredir a Eli notó que seguía poniéndolo en práctica en situaciones parecidas, por ejemplo, con sus amigos de la secundaria y con sus vecinas (Ver esquema 2).

\section{Discusión de los resultados}

Para orientar la descripción de algunos de los resultados se retoma una de las preguntas de investigación: ¿Qué características poseen las experiencias lectoras escolares construidas por alumnos de segundo grado de secundaria? de la cual se desprenden tres cuestiones subsidiarias.

La primera, ¿ ¿ómo se construyen las experiencias lectoras escolares?, dio origen a la dimensión epistemológica, en la cual se recurrió a la perspectiva analítica de la Fenomenología de Schütz $(1993,1995)$ que se refiere a que en un principio los Actos de la vida cotidiana son intencionales y se completan mediante la acción. Diferentes Actos intencionales integran un Acto completado. Actos completados se reúnen en lo experienciado (la experiencia). Las expe- 
Esquema 1. Red lectora de Berenice

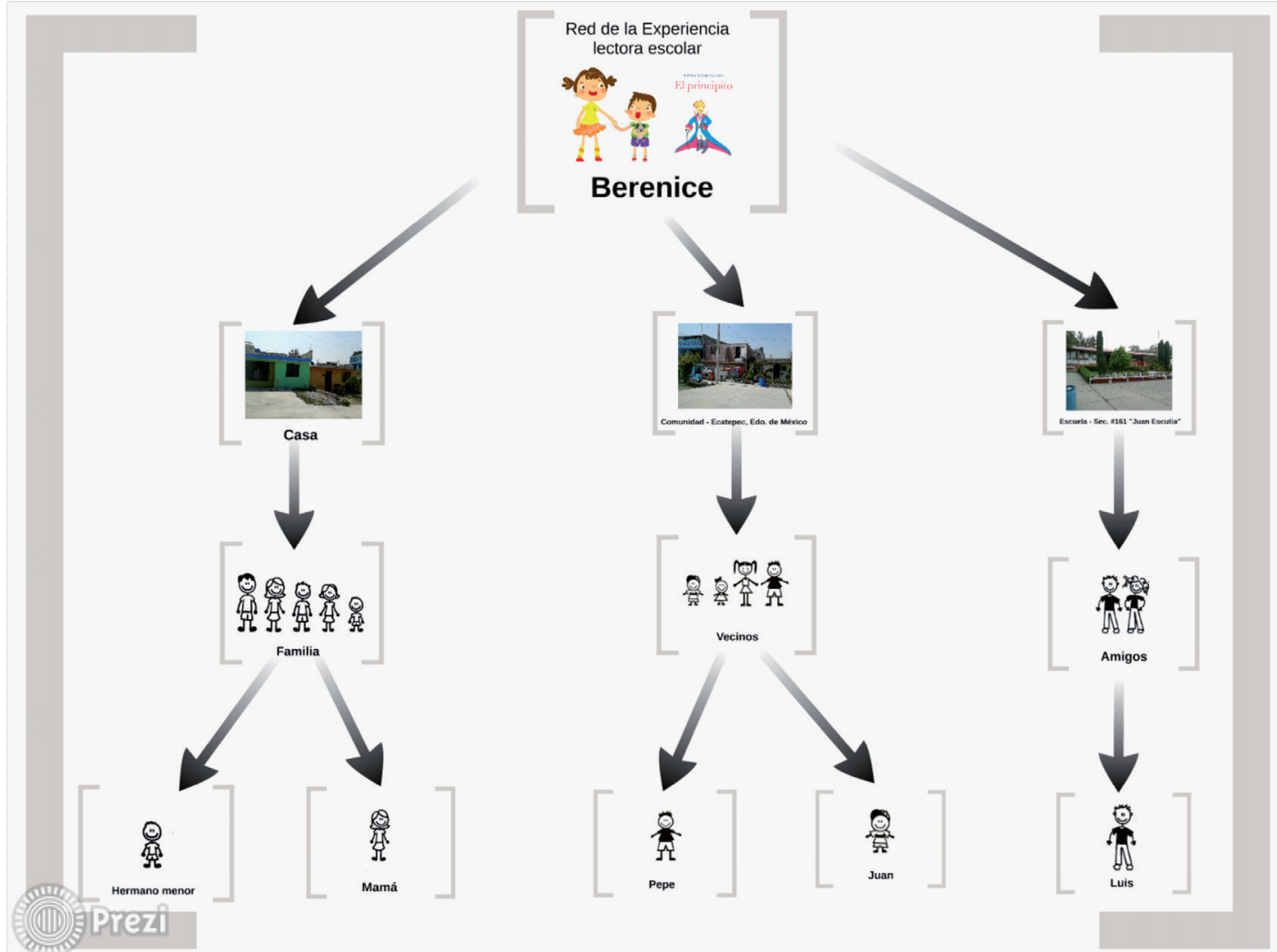

Esquema 2. Red lectora de Nayeli

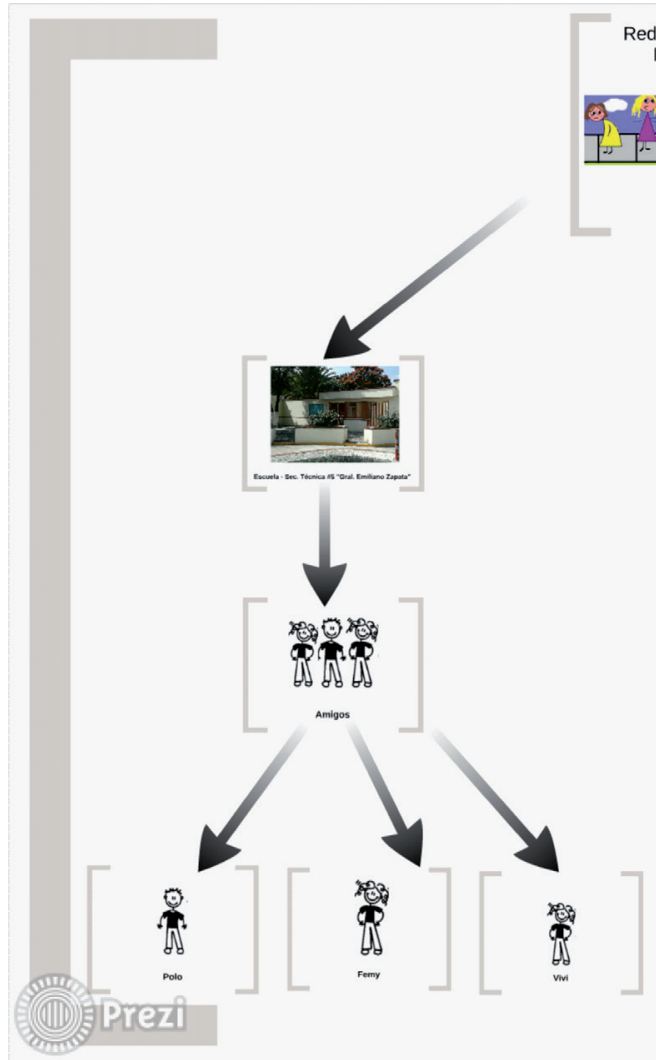

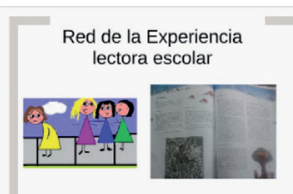

Nayeli
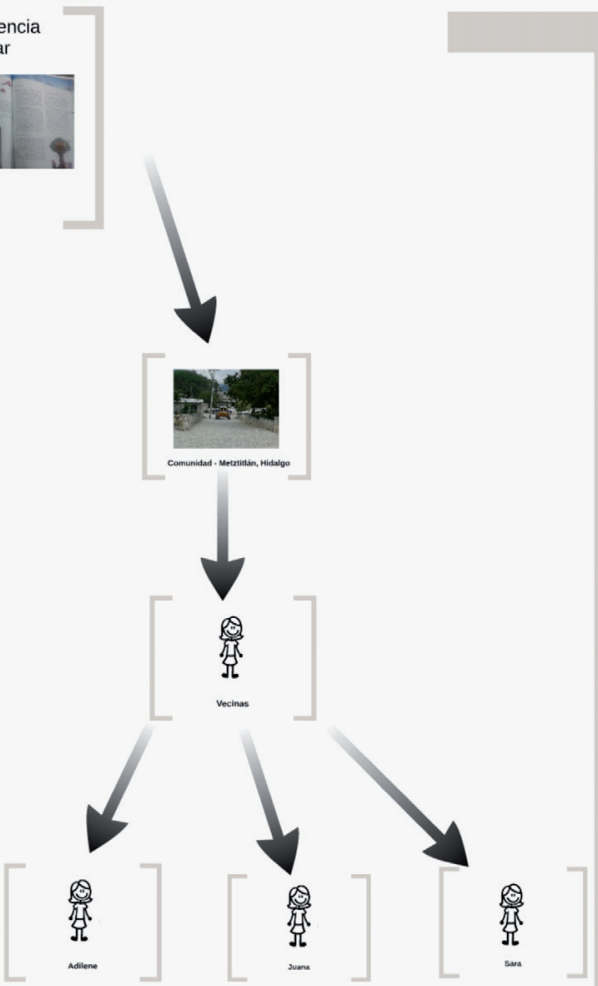

27

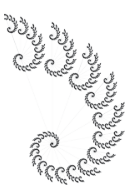


REVISTA DE INVESTIGACIÓN EDUCATIVA DE LA REDIECH N. 7

ISSN: 2007-4336

riencias pueden agruparse en Contextos de experiencia y los Contextos de experiencia forman parte del Contexto total de experiencia. Por lo tanto cuando el actor-alumno realiza actividades en la escuela, como leer, efectúa actos que entretejen la estructura de una experiencia, que a su vez forma parte de una urdimbre más compleja: el contexto total de experiencia.
Por supuesto que sería imposible ubicar los actos que componen en su totalidad estructuras de esta envergadura, pero se rescataron unos cuantos del referente empírico para ejemplificar la dimensión epistemológica de la experiencia lectora escolar de Berenice (Ver esquema 3) y de Nayeli (Ver esquema 4)

Esquema 3. Estructura de la experiencia lectora escolar de Berenice

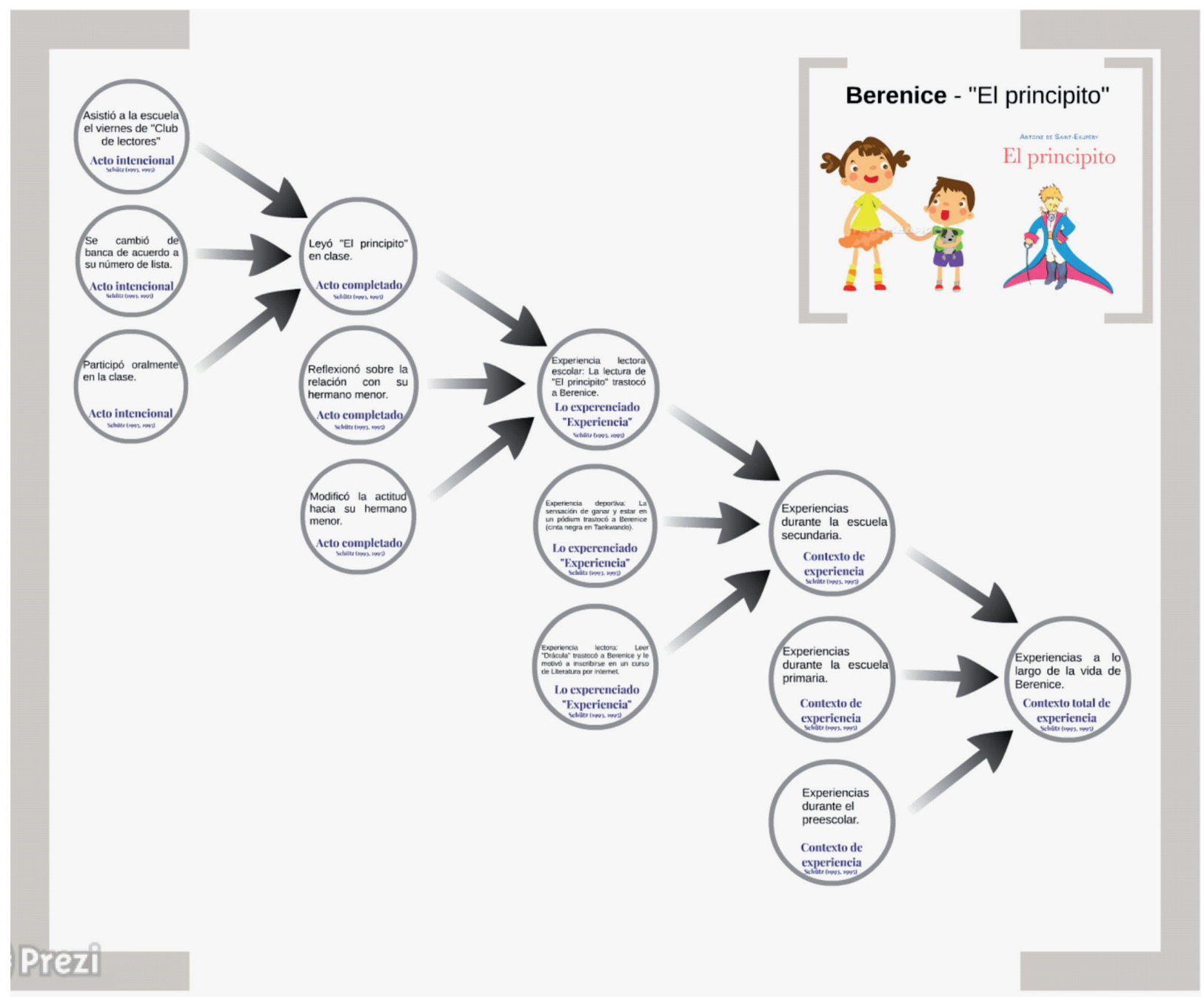


Esquema 4. Estructura de la experiencia lectora escolar de Nayeli
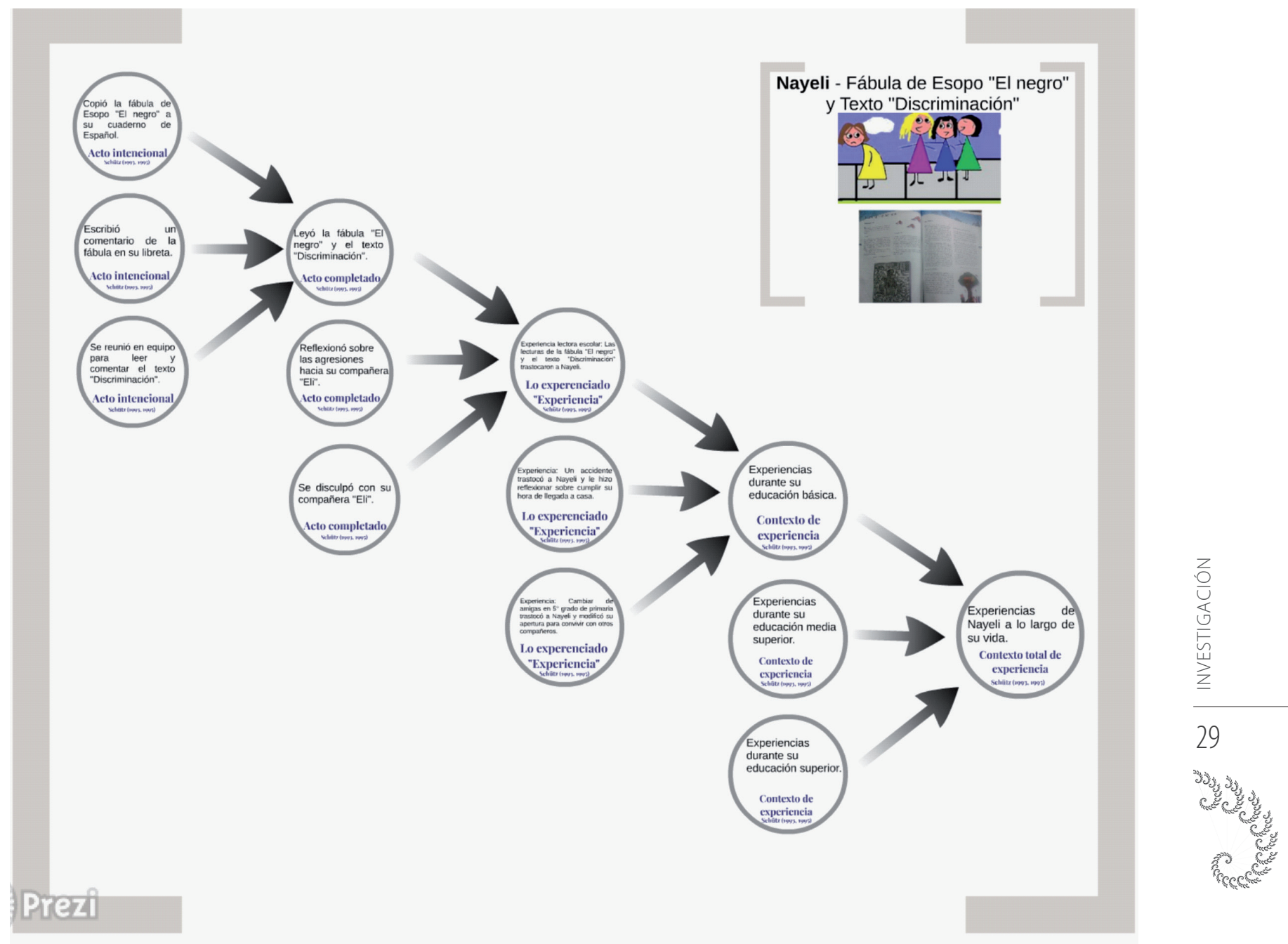

La segunda interrogante ¿qué siente el alumno mientras vive una experiencia lectora escolar?, delineó la dimensión estética. Los planeamientos teóricos de Mandoki $(2006,2008)$ que sugieren modificar la orientación de los estudios de la estética hacia el ámbito social, preponderaron el sentido sensible que se produce al leer. Y según este autor, durante el trabajo de campo se reconoció una estrecha relación entre la condición de estesis y la lectura.

Después de identificar cómo la sensibilidad de Berenice y Nayeli se vincula con su entorno escolar, se formuló la siguiente pregunta: ¿cómo nombrar la fusión entre la condición de estesis y el acto de leer?, lo cual condujo a sopesar la posibilidad de que hubiese un nuevo sentir o de que un sentir distinto se agrega al existente como una pieza más de su constitución. En otras palabras: Berenice al leer El principito poseía un sentir que comprendía la preocupación por los conflictos entre sus padres, intranquilidad por agresiones verbales de sus compañeros de clase y tensión por la relación con su hermano menor. Al construir 
su experiencia lectora escolar ella expresa que se produce "otro" sentir: "[...] remordimiento, culpa y decepción de mí misma [...]" (D27EP-AB2-08/05/2014: 13).

Por su parte Nayeli tenía presente el abandono de sus padres, el rechazo de su abuelo materno y los problemas con sus abuelos y familiares con los que vive. Al leer la fábula El negro y el texto Discriminación percibe también un sentir distinto, el de Eli que padecía las hostilidades por parte de otros alumnos: "[...] me hizo sentir lo que ella estaba sintiendo [...]" (D26EPAN2-29/04/2014: 8).

Así que, al revisar la categoría de estesis de Mandoki $(2006,2008)$ se llegó a la conclusión de que no se trata de otro sentir sino del sentir en sí mismo, solo que al vincularse con el acto de leer se produce lo que se ha denominado: coyuntura estética, que en esta investigación es otra categoría intermedia (Buenfil, 2008).

Para expresar dónde se ubica la coyuntura estética en la experiencia lectora escolar se elaboraron los esquemas 5 (Berenice) y
6 (Nayeli), en los que se expresa con la ubicación de un triángulo cómo el acto de leer es infiltrado por la estesis existente, prolongándola hasta lograr que el lector/alumno establezca una relación entre el texto y la estesis de su vida cotidiana, provocando un punto crucial en la asociación de estos dos aspectos.

Es justamente en este triángulo que la coyuntura estética hace acto de presencia. Cabe aclarar que este punto es parte de la condición de estesis del actor/alumno, puesto que además de que no se señala que haya una nueva estesis, tampoco se pretende manifestar que el sentir puede ser fragmentado como el de la escuela, el de la casa, el de los amigos, el de la lectura; sino únicamente especificar que se intersectan la condición de estesis y el acto de leer en una especie de articulación que forma parte de la construcción de la experiencia lectora escolar. Por ello se utilizó el término coyuntura, porque al expresar la intersección entre estos dos elementos se intenta resolver cómo expresar la existencia de un fenómeno estético escolar.

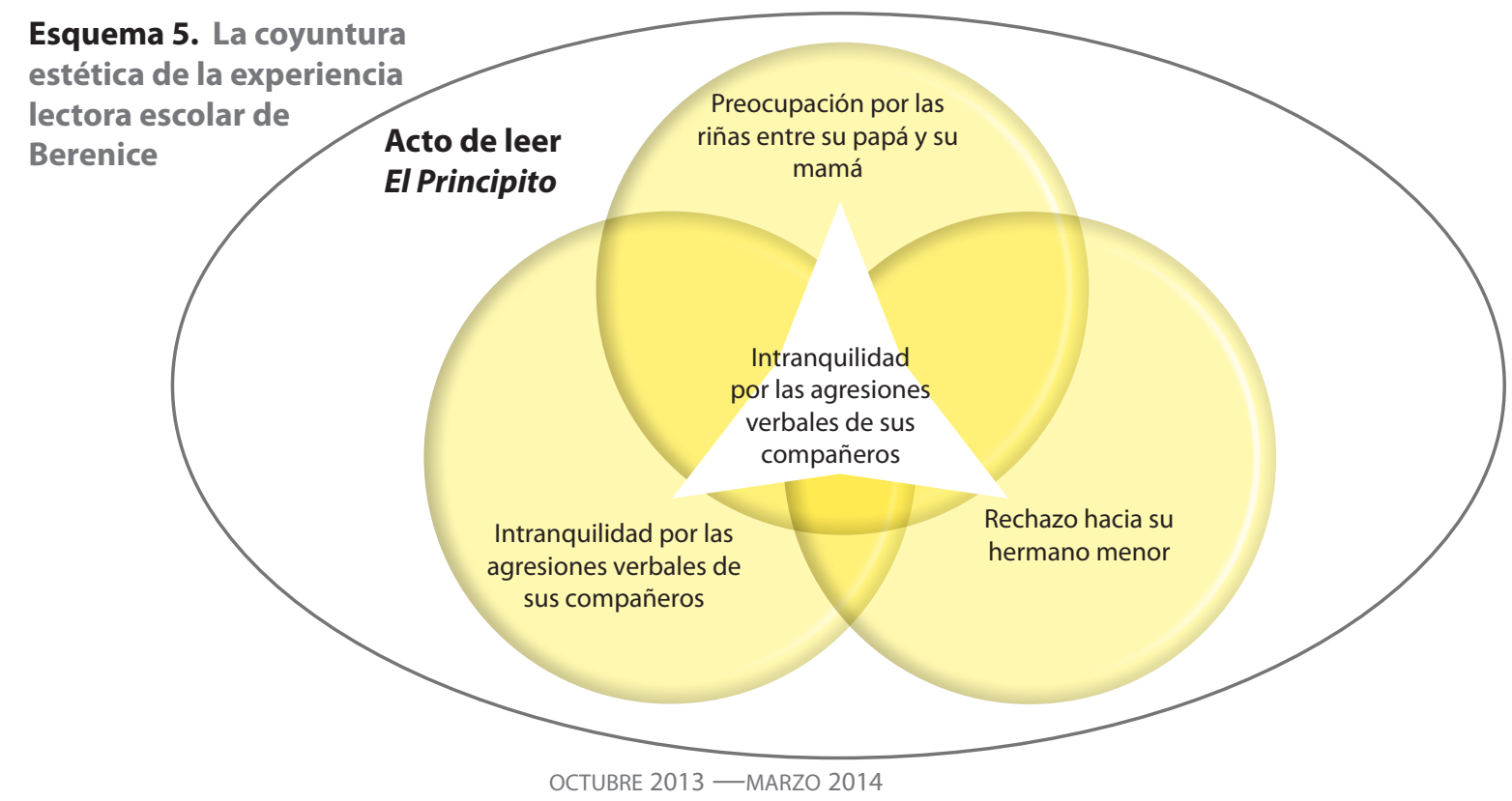




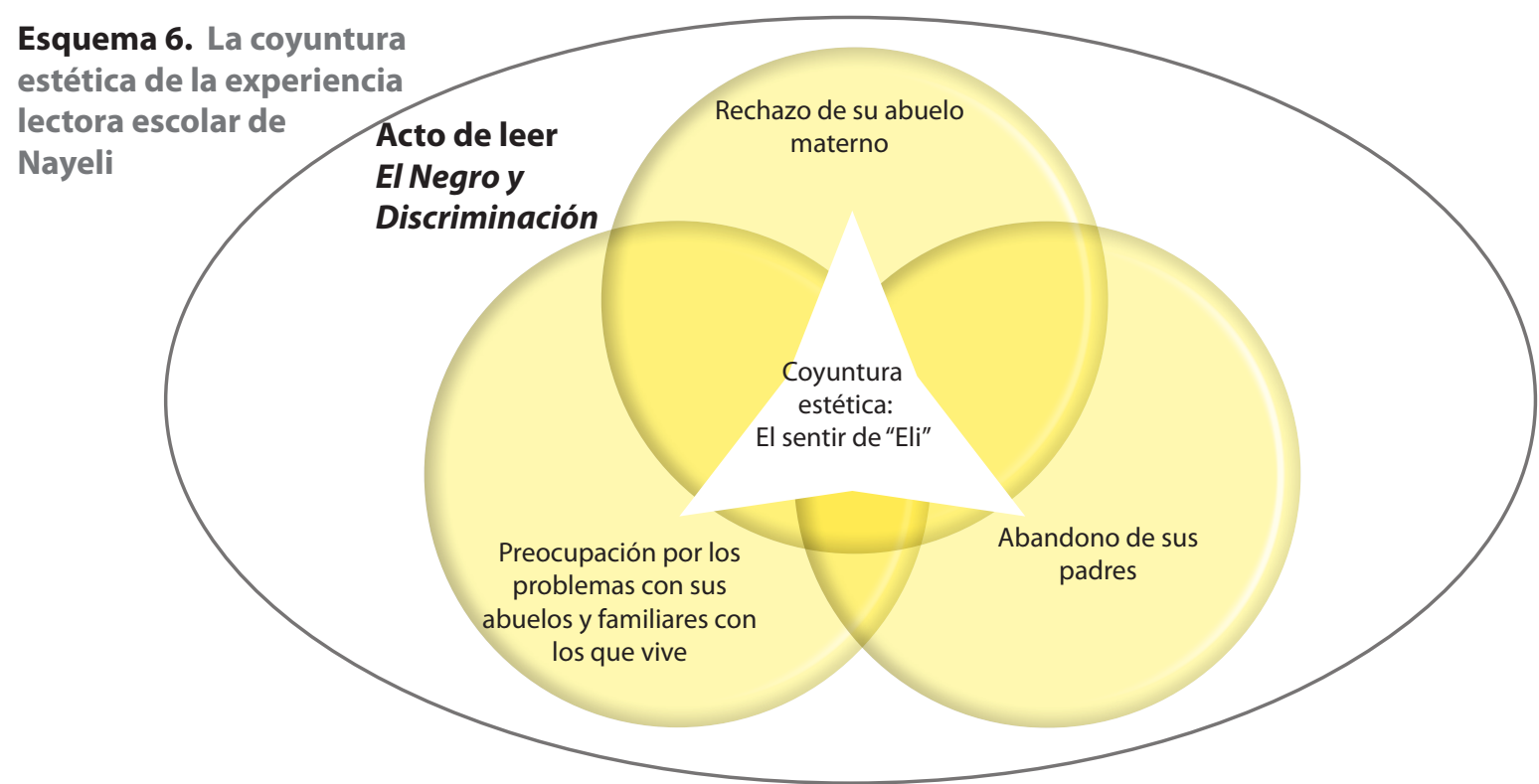

La tercera pregunta ¿con qué elementos del texto se identifica el actor-alumno al construir una experiencia lectora escolar? fue la que guió la dimensión sociocultural.

En ocasiones, al impartir la asignatura de Español, se intenta recuperar las características socioculturales del actor/alumno para trabajar la lectura en el aula de clases. Así lo expresa la maestra Mirna de Ecatepec, Estado de México:

E: Cuando me dice que buscan lecturas que les interesen, que les atraigan...

PM: Ajá, procuro que sean así como que graciosas, curiosas, que despierten lo que ellos ya tienen: la curiosidad, o que... que sean de personajes de su edad, que sean con adolescentes o textos que sea con valores, a lo mejor luego eso no...no lo entienden a la primera y hay que interpretarle pero que...que sean positivos para ellos (D24EPPM3-11/04/2014: 3).
El profesor Sergio de Metztitlán, Hidalgo comparte ese punto de vista:

"[...] todas las lecturas deben hacerse significativas, esto es que el alumno debe identificar qué vivencias, qué situaciones son muy parecidas a su vida, a su contexto y... y eso es una manera de... de vincularlo más con la literatura" (D17EP-PS2-27/11/2013: 2).

A pesar de que en el trabajo de campo se apreció que los profesores de Español que participaron en la investigación compartían esta concepción, resultó que en los casos de sus alumnas (que construyeron una experiencia lectora escolar) la relación que establecieron con los textos no obedeció a esta línea de trabajo. Berenice y Nayeli pusieron en práctica una perspectiva distinta de lo sociocultural: se identificaron con el texto, no por compartir características socioculturales similares a su vida cotidiana. La primera relacionó dos personajes con 
ella y su hermano. Mientras que la segunda se identificó con la situación descrita en los textos.

Para cerrar el presente trabajo es pertinente comentar que esta investigación no resuelve la problemática de la lectura en las escuelas secundarias, el objetivo se centra en aportar elementos que propicien la reflexión sobre ello.

\section{Notas}

1. A nivel nacional a partir de 2006 se aplica la Evaluación Nacional del Logro Académico en Centros Escolares (ENLACE).

2. A nivel internacional la Organización para la Cooperación y el Desarrollo Económico (OCDE) evalúa la competencia lectora en más de 60 países, entre ellos México que en el año 2000 se incorporó al Programa Internacional de Evaluación de Estudiantes (PISA).

3. A nivel federal el "Programa nacional de lectura y escritura", a nivel estatal el programa "Leer para crecer".

\section{Referencias}

Barthes, R. (2004). El placer del texto y lección inaugural. Décimo quinta edición en español. Siglo XXI Editores. México.

Buenfil, B. R. N. (2008). "La categoría intermedia” en
Cruz, P. O. y Echavarría, C. L. (Coordinadoras). Investigación social: Herramientas teóricas y Análisis Político de Discurso. Primera edición, Programa de análisis político de discurso, Casa Juan Pablos, Centro Cultural S. A. de C. V. [En línea]. México, Recuperado 20 de Junio de 2013 en: http://www.die.cinvestav.mx/Portals/0/SiteDocs/Investigadores/RBuenfil/ Capitulos/LaCategoriaIntermedia.PDF

(2011). Apuntes sobre los usos de la teoría en la investigación social. Consideraciones metodológicas en investigación social. 2da. Edición, LAPLAMBERTH Academic Publishing GmbH\& Co. KG. U. S. A.

Freire, P. (1986). La importancia de leer y el proceso de liberación. Cuarta edición en español, Siglo XXI Editores. México.

Mandoki, K. (2006). Prácticas estéticas e identidades sociales. Prosaica Dos. Siglo XXI Editores. México.

(2008). Estética cotidiana y juegos de la cultura. Prosaica Uno. 2da. Edición. Siglo XXI Editores. México.

Rodríguez, G., et. al. (1999). Metodología de la investigación cualitativa. Ediciones Aljibe. España.

Schütz, A. (1993). La construcción significativa del mundo social. Primera Reimpresión, Ediciones Paidós. España.

(1995). El problema de la realidad social. Trad. Néstor Míguez. Amorrortu, Segunda Edición. Argentina.

Taylor, S. J., et. al. (1987). Introducción a los métodos cualitativos de investigación. Editorial Paidós. España. 